\title{
A PRELIMINARY EXPLORATION OF THE RURAL-URBAN DIFFERENTIAL IN LANGUAGE AND SPEECH DEVELOPMENT AMONG CHILDREN WITH DOWN'S SYNDROME.
}

\section{Catherine Waithera Ndung'u}

\begin{abstract}
Speech and language are key issues for all human beings because it is through them that people share feelings, ideas and emotions. The Down's Syndrome children have been defined as those who have deficits in physical features and are mentally retarded. Their mental incapability bring about delays in speech and language development. The social development theory by Vigotsky informed this study. The theory states that social interaction plays a fundamental role in the process of cognitive development. Since language is a cognitive aspect, it can therefore develop effectively as children interact with the society. Down Syndrome children in rural settings were found to develop speech and language much slower than their counterparts in urban settings. This was because they were denied interaction with others especially in school due to the stigma attached to mental handicapping conditions in the society they lived. This was found to deprive them of important social, economic, political and cultural benefits since speech and language are key to socialization and education. I argue that interventions concerning the speech and language development of Down Syndrome children need to be applied uniformly in both rural and urban settings, to enable all Down Syndrome children be prepared to become active participants in nation building later in life when they become adults.
\end{abstract}

\section{Introduction}

Speech and language are essential for every human being because it is through them that one shares feelings and ideas. Speech and language are tools that humans use to communicate or 
share thoughts, ideas and emotions. ${ }^{1}$ Language is the set of rules shared by the individuals who are communicating that allows them to exchange thoughts, ideas or emotions while speech is talking which is one way that language can be expressed. De Saussure, in his collection of notes published by his students Charles Bally and Albert Sechehaye in 1916 argues that language is divided into langue(language) and parole (speech). He refers langue to the abstract system of language that is internalized by a given speech community and parole as the individual acts of speech. De Saussure argues that while speech(parole) is heterogeneous, that is, composed of unrelated or differing parts or elements, langue( language). is homogeneous, that is, composed of the union of meanings and sound images in which both parts are psychological ${ }^{2}$.It is therefore difficult to separate language from speech.

Down's Syndrome is a combination of birth deficits including some degree of mental retardation and characteristic facial features. About 30-50 percent of babies with Down's Syndrome also have congenital heart defects and many have some visual and hearing impairment and other health problems. ${ }^{3}$ The condition is medically referred to as Trisomy 21.It is referred to as Trisomy 21 because; a baby normally at conception inherits genetic information from its parents in the form of chromosomes; 23 from the mother and 23 from the father. A Down syndrome child gets an extra chromosome 21 which makes the total number of chromosomes to rise to 47 in lieu of 46 . It is believed that this extra chromosome causes developmental delays associated with Down syndrome. Since speech and language are mental activities, their development are also affected in the process. Experts claim that the prevalence of the Down syndrome is 1 in every 800 or 1000 births and that the incidence rises with increasing maternal age, Shriver (2010).

Children with Down syndrome often have speech and language problems (Kay, 1999). Studies have shown that when placed in a stimulating environment, children with Down

\footnotetext{
$1 \quad$ http://www.nidcd.nih.gov/health/voice/speechandlanguage.asp

$2 \quad$ http://en.wikipedia.org/wiki/course-in-general-linguistics

$3 \quad h t t p: / / w w w \cdot h e a l t h s c o u t . c o m / e n c y / 68 / 449 /$ main.html.
} 
Syndrome learn better than others who do not learn is a stimulating environment (Seo, 2010). This study sets to examine how the rural and urban settings offer stimulation which in turn determines the rate at which the Down syndrome children develop speech and language.

Issues pertaining to speech and language development in Down syndrome children have been researched in the developed countries and strategies put in place to assist Down syndrome children socialize and also achieve academically. This is evident from the work of Buckley and Bird (2001). Unfortunately, developing countries, Kenya included, are still struggling with issues of 'regular' children thus ignoring special needs education (SNE) issues, which Down syndrome is a part of. This paper sets to look at the development of speech and language of Down syndrome children in the rural and urban settings. The objective is to establish the causes of the difference in speech and language development of Down Syndrome children between rural and urban settings.

\section{History of Down syndrome}

According to Leshin (2003), the formal story began in 1886, when a physician named John Langdon Down published an essay in England where he described a set of children with common features that were distinct from other children with mental retardation. Down was superintendent of an asylum for children with mental retardation in Surrey, England when he made the first distinction between children who were Cretins (later to be found to have hypothyroidism). He referred to these as "Mongoloids".

Down based this unfortunate name on his notion that these children looked like people from Mongolia, who were thought then to have an arrested development. This was seen as an insult by early genetic researchers from Asia in 1960s and spurred a lot of complaints which saw the drop of the term from scientific use. Instead, the condition was called "Down's Syndrome" in honour of Langdon Down.

There was much speculation about the cause of Down syndrome in early $20^{\text {th }}$ century. Waardenburg and Bleyer in 1930 were the first people to associate Down syndrome with 
chromosomal abnormalities. Later, in 1959, Jerome Lejuene and Patricia Jacobs, working separately, determined the cause to be trisomy (triplication) of the $21^{\text {st }}$ chromosome.

\section{Symptoms of Down syndrome}

Down's syndrome children exhibit various symptoms that fall into three major categories. One, physical appearance that may include; eyes slanted upwards, small ears, flat back of head, small mouth, protruding tongue, flattened nose bridge, white spots on the iris, short fingers, broad hands with a single crease across the palm, loose skin on the back of the neck, loose joints, poor muscle tone, low birth weight, vertical skin folds between the upper eyelids and inner cornea of the eye. Two, learning difficulties that may include; memory problems, low attention span, difficulty in problem solving and difficulty in understanding the consequences of their actions. Three, delayed development in areas of learning to crawl, speak, read and social skills necessary for social interaction. This paper concentrates on delayed development in the area of learning how to speak.

\section{Theoretical framework}

The study was anchored on the social development theory by Lev Vygotsky (1876 - 1934). The theory argues that social interaction precedes development. It works within three main tenets. One, that social interaction plays a fundamental role in the process of cognitive development. Vigotsky argues that social learning precedes development. That a child's cultural development occurs in two levels; first on the social level(interpsychological) and later in an individual level ( intrapsychological). Two, the More Knowledgeable Others ${ }^{4}(\mathrm{MKO})$. The MKO refers to anyone who has a better understanding or a higher ability level than the learner, with respect to a particular task, process or concept. MKO is normally thought of as being a teacher, coach or older adult, but the MKO could also be peers, a younger person or even computers. Three, the Zone of Proximal Development (ZPD). The ZPD is the distance between a student's ability to perform a task under adult guidance and/or with peers collaboration and the student's ability in solving the problem independently. According to Vigotsky,

\footnotetext{
${ }^{4}$. http:// www.nhs.uk/conditions/downs-syndrome/pages/symptoms.aspx
} 
learning occurred in this zone. This paper considered the Down syndrome children as social beings that developed language from interacting with others. While those from rural settings, in this case Gatundu district, are denied social interaction from the MKO, their speech and language tend to be affected, those from urban settings, in this case Thika Municipality, who are exposed to the MKO are advantaged and develop speech and language faster. This theory explains clearly the importance of social interaction by the Down's Syndrome children if they are to develop sufficient language.

\section{Speech and language problems of Down syndrome children}

Down syndrome children experience speech and language problems. Kumin (1994) observes that although there are common speech and language problems, there is no single pattern of speech and language common to all children with Down syndrome. She asserts that many children with Down syndrome have more difficulty with expressive language than they do with understanding speech and language, that is, receptive language skills are usually more advanced than expressive language skills. Certain linguistic areas such as vocabulary are usually easier for children with Down syndrome than other areas such as grammar. Sequencing of sounds and of words may be difficult for many children. Many children have difficulties with intelligibility of speech and articulation. Kumin (Ibid) continues to note that some children use short phrases, while others have long conversations.

Kumin (2010) argues that Down syndrome children have good social interactive skills and use gestures and facial expressions effectively to help them communicate. However, syntax and morphology (including grammar, verb tenses, word roots, suffixes and prefixes) are more difficult areas possibly because of their complex and abstract nature.

In Kenya, most Down syndrome children are not taken to school because they are seen as not fitting in our school system especially with the speech and language problems. A further factor of failure to take them to school is the stigma associated with children with disabilities in the society. The Down Syndrome Society of Kenya (2009) observes that persons suffering from Down Syndrome in Kenya face huge obstacles that include open hostility and discrimination, exclusion from education and higher levels of poverty and vulnerability. The society observes 
that children with Down syndrome experience speech and language problems. i.e. difficulties in understanding verbal instructions, abstract concepts and explaining how tasks have been carried out. They are therefore hidden at home and sometimes mistreated as they are seen as a bad omen. However, this notion is changing and with the inception of special need education (SNE) in the 1990s, some Down syndrome children have been brought out in the light especially recently when the government started funding SNE.

In assessment centres, which is the first point of SNE, Down syndrome children are found to have no speech or just very little speech and language. This is mainly so in those from rural areas than those from urban areas. The Down syndrome children in rural areas are seen to be more withdrawn than those in urban areas. After assessment, the Down syndrome children are placed in nearby special needs institutions being special classes in the regular primary schools or in special boarding schools. This paper looked at Down syndrome children in rural and urban special institutions and tried to establish speech and language behaviour both at entry and after one or two years of school.

The following are examples of cases taken from this study of rural special units in Gatundu district and urban special units in Thika municipality.

\section{1) Mang'u Special Unit for the intellectually challenged which is in a rural setting - Gatundu District.}

\section{Rose Wambui - 7 years Down syndrome child in Mang'u Special Unit.}

The special unit teacher, Mary Ndung'u, reported that Rose had literally no speech when she was enrolled in September 2008. She had not attended any pre-school because the mother feared that she could get lost since the nearest pre-school was about one kilometer away. Besides, the child had no speech and had characteristics associated with curses in the society like stunted growth and mental retardation popularly termed as a fool. So, she hid her in the house. When her other children alerted her that a special unit was established in their school, she came to consult whether Rose could fit in the unit and emphasized that she could not talk. By December 2008, she had acquired the word "bye" which according to Ms Ndung'u was a step forward since Rose was withdrawn and quiet. 
Ms Ndung'u reported that she tried a number of things in a bid to develop Rose's speech and language because she realized that she could respond to instructions. Some of these strategies that stimulated Rose included: -

\section{1) Interaction with peers}

The teacher would place Rose in pre-school always after break and in the afternoons when they had free activities. She observed that Rose soon began to tussle with others as they snatched playing objects and rushed to the teacher to report her offenders when angry. Vocabulary began flowing.

\section{2) Using play materials}

A ballooned doll was one that carried Rose's attention the whole morning. She would struggle filling air in it, an activity that made her speech organs flexible. After the doll took shape, she would role -play a mother to it and kept talking to it. Although the speech was not intelligible at first, later the teacher could comprehend what she was telling the doll, like "oma” (sleep).

\section{3) Engaging her in arguments}

Rose participated in the low-ability category of Provincial Special Sports and Games in Central Province where she was selected for Nationals. She was rewarded a trophy, a thing that excited her. The teacher continually engaged arguments with Rose that she would not go for sports and games. Rose would plead with the teacher on daily basis bringing a lot of vocabulary with it.

\section{4) Trips and excursions}

Ms Ndung'u took her children to Thika Town for a trip. The most exciting thing for them was using the lift up and down a tall building (Thika Arcade)... This excited Rose who kept talking about it both at home and at school.

\section{5) Daily life activities}


Involving the child in daily life activities and sending her even to the staff room. This built her confidence and is no longer ashamed even when she cannot pronounce the words correctly.

\section{6) Singing}

The teacher used simple common songs and after singing the same song several times, she requests individual children to sing alone. First she requests fluent children before asking Rose to sing alone. Having built her confidence, Rose will sing even if it is repeating a word or two.

Currently, Rose is able to understand even Kiswahili although she responds to Kiswahili questions in mother tongue i.e Gikuyu. Her answers to questions were short, characterized with absent first syllables. However, she interacts comfortably with people and can even volunteer to ask a question. These were some of her interactions with the researcher.

\section{Kiswahili}

Unaitwa nani? : _ose_ambui (Omits R and W)

What is your name? -Rose Wambui

Hii ni nini? : ___ate (Omits müg)

What is this -Bread

Yuko wapi mami?

athiĩ

Where is your mother?

-She has gone

\section{Kikuyu}

Ĩno nĩ kĩ̃? imũ (omits th)

What is this? (Pointing at a phone): Phone 
Ekũ mwana?: $\quad$ athiĩ

Where is the child? She has gone

Mena ũ? : _ _ a mum (Omits n)

With whom? with mum

Rose's speech was characterized by omissions mainly at the beginning of the word. Her language was scanty but comprehensible. Ms Ndung'u asserted that there had been gradual improvement on her speech and language and was optimistic that given time, Rose would acquire fluency in both mother tongue and Kiswahili. We now turn to the second subject, Daniel Gachiengo.

\section{Daniel Gachiengo - 17 years of Mang'u Special Unit}

The teacher reported that he joined school late at age 15. He was orphaned and lived with the grandmother. He had been isolated from people except on Sundays when they went to church. This was because he was problematic and would get lost after following strangers. The grandmother built him a small room and provided him with a piece of timber that he assumed to be a piano. This kept him busy long hours singing church hymns and praying, imitating what he saw at church. Ms Ndung'u said that Daniel (Dan) had no speech when he was enrolled but could let out a tune-like sound like church hymns.

Dan continued to improve in speech although with difficulties. When interviewing him, he kept shying off and bringing other issues concerning food, like

$\begin{array}{ll}\text {-Ũtie niĩ } & \text {-tũye- } \\ \text { I am hungry } & \text { let us eat }\end{array}$

These were some of the speech he had when interviewed in Gikuyu;

Ũỹ̃ nũũ? - - $\quad$-aimũ for mwarimũ (omits $m w a$ )

Who is this? (Pointing at the teacher) -teacher 


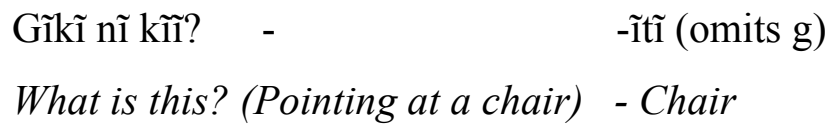

Interestingly, he picked a piece of wood, assumed that it was a piano and composed a song for us full of praises:

Uuuuuuu - aimũ -itũ uuuuuuuuuuuuu -ega

ииииии оur teacher иииииии good

And repeated this until you stopped him.

We now move to examine the rural setting.

\section{2) Kenyatta Special Unit for the Intellectually Challenged (I.C.)}

This is located in Thika Municipality in an urban setting. The following were two examples of Down syndrome children taken from an urban setting.

\section{a) John Mwangangi (10 Years)}

John was taken to school early at 6 years. When he was enrolled he could respond to questions but in mother tongue (Kikamba). The class teacher Ms Ruth Aluko said that he gave one word for a sentence, for instance:

Habari yako - $\quad$ kuseo (kikamba)
$\begin{aligned} & \text { How are you? } \\ & \text { I am fine }\end{aligned}$
Who has brought you? $\quad$ Father

Later, John developed Kiswahili because the teacher and other learners used Kiswahili. His speech and language had gradually improved and by the time of this study, he could 
give more detailed answers. Mr. Njoroge added that John reported whenever someone beat him like "Kamau piga mimi hapa"(Kamau beat me here) pointing at the place. When interviewing John, this is what he had: -

Sasa John - Poa ( this is sheng, a language loved by the youth in Kenya)

How are you? (Greetings) fine

Ulikula nini? - $\quad$ Nilikula mchele na [ngima] mboga (there is language mixing here)

What did you eat? - I ate rice and ugali cabbage

Uliletwa na nani $\quad$ - $\quad$ Mtu pale nabeba

Who brought you? - Someone there is carrying

We now examine another subject from an urban setting.

\section{b) Joy Olive Wambui - 5 Years}

Joy was taken to school early and interacted with others. She was enrolled the year prior to this study and already had some speech although not intelligible. She mainly made use of gestures to complement her little speech. Teacher Pauline said that she was developing speech and language fast. An interview with Joy elicited the following: -

Hii nini? - Wawa (instead of raba)

What is this (showing a rubber) rubber

Hii ni nini? $\quad-\quad$ Kuku

what is this (showing a book) book

Sasa - tata (she mis-repeats the greeting instead of responding)

Joy had problems in articulating many syllables but she understood everything she was asked and made efforts to respond. The teachers were optimistic that she would gradually 
develop fluent and intelligible speech and language. According to these teachers, some of the factors that contributed to fast development of speech and language in Down syndrome children were: -

- Exposure

- Interaction with peers

- Playing with materials

Encouraging parents who are ready to offer information even when little improvement is noted.

- Supportive parents who provide necessary learning materials and take time to be with the child.

\section{Findings}

Looking at the above study, it was established that the speech and language entry behavior of children with Down syndrome differed between rural and urban settings. Theoretically, the rural Down Syndrome children were denied the interaction of the MKO as opposed to the Down Syndrome children who enjoyed full interaction from the MKO. Those from rural settings seemed withdrawn and unwilling to interact with others as opposed to those from urban areas who were friendly and willing even to use gestures to express what they wanted. This was attributed to the fact that those in the rural settings were hidden in the houses sometimes to a point of not seeing the sun. They lacked exposure and interaction with other people which impeded speech and language development. In contrast, those in urban settings were exposed to many people and materials that aroused their interest. We established that Down syndrome children from urban settings were vibrant and jovial and responded to all questions even when they did not have correct answers. This showed that they had confidence in the people around them.

Another finding was that Down syndrome children from rural settings were not taken to school early. As late as 17 years, Dan had not gone to school apart from church on Sundays. School is a major agent of socialization, ${ }^{5}$ thus Down syndrome children from rural settings missed a lot of opportunity to socialize and learn from their peers. This was different from their counterparts

\footnotetext{
5 http://www.cheathouse.com/essay/school-socialisation-agent.
} 
from urban settings who were taken to school early hence their speech and language development was enhanced.

It was also found that playing materials were used by teachers from both rural and urban settings. This was found to enhance speech and language development even when the Down syndrome children were older (Dan's case). A further finding was that parents played a major role in speech and language development of Down syndrome children. Enlightened parents (from urban setting) were seen to offer support to their Down syndrome children without being pulled back by the stigma of siring handicapped children. This was seen in the way the Down syndrome children were exposed and taken to school early (rural setting; 10 years and above, urban setting; as early as 5 years). Provision of materials and even feeding of the children was also attributed to enlightened parents who were willing to buy what was required for their children and fed them appropriately. They made follow-up of their children's progress closely and reported even slight improvement on speech and language development of their children. Rural parents of Down syndrome children on the other hand were naïve and were seen to view school as a dumping place for their Down syndrome children whom were found difficult and adding no value to their lives. Provision of materials and support was minimal and the parents had to be pushed to do so.

\section{Recommendations}

After exploring the speech and language development in Down syndrome children, it was found that teachers in the rural setting were struggling to assist their learners in all ways possible. The study established that Down syndrome children in urban settings were advantaged than those in rural settings. The study therefore recommended that: -

- To enhance speech and language development of Down syndrome children, the children need to be exposed early in life to the environment surrounding them. The people, animals and objects in the neighborhood need to be allowed to interact with the Down syndrome children in order to stimulate them. This also enables the Down syndrome child to develop confidence from an early age.

- The Down syndrome children need to be taken to school early. This allows the Down syndrome child to interact and socialize with peers who have a positive impact on the Down syndrome child's speech and language development. 
- Playing materials need to be availed to Down syndrome children. These materials stimulate Down syndrome children to try and speak to the materials especially in role-play. The Down syndrome children get attached to these materials which in turn spur their mental activities which speech and language are part of.

- All people need to be educated on issues concerning disabilities. This sheds light to them when they sire children who have Down syndrome. It helps them understand what to do and offer support to their children.

\section{References}

Buckley, S. J. and Bird, G. (2001). Speech and Language Development for Children with Down Syndrome(5-11 years). http://www.downsyndrome.org/information/ Language/childhood. Retrieved on 6/6/2010.

Down Syndrome Society of Kenya, (2009). Living with Down Syndrome. http://www.dssk.org/ Living-with-down-syndrome. Retrieved on 24/6/2010.

http://www.nided,nih.gov/health/voice/speechandlanguage.asp Speech and Language - retrieved on $9 / 6 / 2010$

http://kidshealth.org/parent/medical/genetic/down-syndrome.html. Retrieved on 9/6/2010.

Kay, N. (1999). Sound Therapy for Children with Down Syndrome: http://www.ican.do. net/sound-therapy-for-children-with-htm. Retrieved on 4/9/2010.

Kumin, L. Goodman, M. Council, C. (1996). Comprehensive Communication Intervention for Infants and Toddlers with Down Syndrome. Hhtp://www.health.com/ speech.htm. Retrieved on 9/6/2010.

http://www.health scout.com/ency/68/449/main.html. Down Syndrome- Symptoms, Treatment and Prevention. Retrieved on 2/9/2010. 
http://en.wikipedia.org/wiki/course-in-general-linguistics. retrieved on 2/9/2010.

http://www.nhs.uk/conditions/Downs-Syndrome/Pages/Syndrome.aspx.- Down's SyndromeSymptoms. Retrieved on 2/9/2010.

Kumin, L. (2010). Speech and Language Skills in Children and Adolescents with Down Syndrome. http://www.ndss.org/index? Option. Retrieved on 11/6/2010.

Leshin, L. (2003). Trisomy 21: The Story of Down. http://www.ds-health.com/trisomy.htm. Retrieved on 9/6/2010.

Seo, I. (2010). Down Syndrome Development: Giving Kids what they Need to Communicate and Grow: http://hubpages.com/hub/down-syndrome-development. retrieved on $4 / 9 / 2010$.

Shriver, E. K. (2010). About Down Syndrome. http://www.nichd.nih/gov/publications/pubs/ Downsydrome.cfm. retrieved on 9/6/2010. 